\title{
ADORNO E OS TIPOS DE COMPORTAMENTO MUSICAL: ATUALIDADE E LIMITES DE UMA CATEGORIZAÇÃO*
}

\author{
Monique Andries Nogueira \\ Universidade Federal do Rio de Janeiro, Rio de Janeiro, \\ Rio de Janeiro, Brasil
}

\begin{abstract}
Resumo: O presente artigo busca promover uma reflexão acerca da atualidade da classificação dos comportamentos musicais, realizada por T. W. Adorno, na década de sessenta do século passado. Em seu ensaio original, o filósofo aponta oito tipos de ouvintes: o especialista, o bom ouvinte, o consumidor cultural, o ouvinte emocional, o ouvinte do ressentimento, o ouvinte de jazz, o ouvinte do entretenimento e o indiferente. Ao fazer essa categorização, Adorno utiliza tanto elementos propriamente musicais, quanto fundamentos sociológicos e psicológicos. Uma vez que uma intensa modificação nos padrões de escuta se deu a partir da crescente revolução tecnológica, poder-se-ia supor que essa categorização se apresentasse inválida. No entanto, concluímos que boa parte de sua análise permanece atual e relevante, pois são pontuais os possíveis anacronismos. O que ressalta aos olhos é que os processos de regressão da audição e de coisificação da música pela indústria cultural permanecem ativos e devastadores.

PalavRAs-Chave: Comportamentos musicais. Teoria crítica. Sociologia da música.
\end{abstract}

INTRODUÇÃO

No inverno de 1961, Adorno realiza uma série de preleções acerca de conteúdos sociológico-musicais na Universidade de Frankfurt. Grande parte delas é transmitida por rádio e apresenta enfoques variados: música ligeira, música de câmara, regente e orquestra, opinião pública, mediação. Em

\footnotetext{
* Artigo recebido em 8/7/2013 e aprovado em 12/10/2013.
} 
1962, Adorno concorda em reuni-las em livro, pois percebe a relevância de tal temática. Afirma, no prólogo da primeira edição, que não pretende concorrer com as exposições sociológicas já existentes, nem modificar o caráter de preleção de seus escritos e, sim, apresentar "uma sociologia da música em que a música significa mais que os cigarros ou os sabonetes das pesquisas de mercado". Para tanto, seria necessário "não só o mero conhecimento informativo acerca dos fenômenos musicais, mas a compreensão integral da música em todas as suas implicações" (ADORNO, 2011, p. 53).

Entre essas preleções, destaca-se o ensaio intitulado Tipos de comportamento musical, no qual Adorno estabelece uma tipologia de ouvintes, utilizando aspectos psicossociológicos para apresentar essas categorias. Em tempos de massivo consumo musical, em que a indústria da música chega a figurar como importante fatia do produto interno bruto de alguns estados e países, torna-se inevitável a questão: Estariam essas categorias ainda atuais? A intensa modificação - tanto nos padrões de produção (refiro-me aqui à crescente sofisticação dos estúdios e técnicas de gravação), quanto nos meios de veiculação (devido à revolução digital que proporciona o surgimento de inúmeros aparelhos para consumo imediato e constante de música) - não teria tornado as categorias adornianas obsoletas? Ao contrário, suas análises a respeito do fenômeno da indústria cultural tornam-se, a cada dia, terrivelmente atuais: é o caso do mecanismo de manipulação retroativa (HORKHEIMER; ADORNO, 1986), no qual os consumidores/ouvintes se convencem de que estão escolhendo o que consumir/ouvir, quando, na verdade, recebem exatamente aquilo que pesquisas de mercado apontaram para nortear a oferta de mercadorias culturais. Basta uma rápida observação acerca do que faz sucesso hoje nas paradas musicais para se perceber o apuro desse conceito.

\section{A PROBLEMÁTICA DE ESTUDOS SOBRE COMPORTAMENTO DE OUVINTES}

Logo de início, Adorno, em seu ensaio, afirma que irá se ocupar da teoria dos comportamentos típicos de escuta musical "sob as condições da sociedade atual" (ADORNO, 2011, p. 55), isso é, a sociedade de meados do século XX. De imediato, podemos pensar que a sociedade do início do século $\mathrm{XXI}$ se apresenta muito diferente daquela de que falava Adorno; por outro lado, devemos reconhecer que muitas das mazelas advindas da consolidação da indústria cultural previstas por ele se colocam absolutamente atuais. Além disso, algumas das características de comportamento analisadas por Adorno se originam de aspectos psicológicos dos seres humanos que se mantêm presentes, sofrendo pouca variação no decorrer das décadas. 
Naquela ocasião, Adorno já reconhecia mudanças em relação ao desenvolvimento dos meios de escuta musical; no entanto, discordava de que o aumento, puro e simples, dessa escuta ocasionaria uma mudança qualitativa no comportamento dos ouvintes:

assevera-se, por exemplo, que os meios de produção mecânicos e de massa teriam, pela primeira vez, levado a música a um número incontável de indivíduos e que, por isso, conforme os conceitos de generalidade estatística, o nível de escuta teria se elevado. (ADORNO, 2011, p. 56)

$\mathrm{Na}$ atualidade, confirma-se sua desconfiança. A revolução tecnológica tem proporcionado um número ilimitado de meios digitais de reprodução da música: CDs players, celulares, ipads, entre outros. No entanto, é perceptível que o aumento do número de horas ligadas a um meio de reprodução não acarretou uma elevação do nível de escuta. Sem entrar na problemática de valoração, o fato é que o padrão de escuta de uma música por um jovem que a ouve no seu iphone, como pano de fundo para suas atividades aeróbicas, não é o mesmo que se tem, em geral, em uma sala de concerto, ou mesmo em ambiente privado quando se coloca um disco com o intuito específico de apreciá-lo. A presença massiva da música na contemporaneidade, por meio da popularização dos aparatos digitais de execução, não garantiu uma democratização do conhecimento musical; pelo contrário, estimulou uma escuta epidérmica, passiva, distante daquilo que Adorno apontou como uma escuta estrutural.

Adorno reconhece as dificuldades da tarefa à qual se propõe: sabe que os tipos de escuta "estão expostos à desconfiança geral da ciência empírica em relação às tipologias e, em especial, da Psicologia" (2011, p. 57). Todavia, não propõe tipos de forma arbitrária, mas, sim, como "pontos de cristalização determinados por considerações fundamentais sobre a Sociologia da música" (p. 57). Também afirma que não produziria uma tipologia de categorias crescentes, partindo de uma escuta de fato adequada até outra no limite oposto da escala, desconexa por completo, pois parte "do princípio de que a problemática e a complexidade sociais também se expressam por meio das contradições presentes na relação entre a produção e a recepção musicais" (p. 57). Lembra ainda que foi a reflexão sobre a problemática social primária da música que o levou a essa tipologia; nesse sentido, entende que essa, caso tivesse recebido um tratamento empírico e fosse testada a contento, possivelmente seria modificada. Isso abre espaço para a justificativa de estudos, como o presente, que buscam refletir sobre a pertinência e atualidade dessa tipologia. 
O marco que regulou a construção das categorias não foram, como de costume, investigações subjetivamente referendadas, o gosto ou as preferências dos ouvintes, mas algo muito mais consistente:

ele se assenta, antes do mais, sobre a adequação ou inadequação da escuta em relação ao que é escutado. Pressupõe-se que as obras são algo pleno de sentido e, em si, objetivamente estruturado, abrindo-se à análise e podendo ser apreendido e experimentado em diferentes níveis de acuidade. (ADORNO, 2011, p. 58-59)

Na citação anterior, Adorno reafirma algo que transparece em vários de seus ensaios que têm a música como objeto: para ele, fruir música é uma atividade altamente cognitiva, integradora, não apenas um mero deleite. Talvez resida aí uma diferença fundamental entre o pensamento estético adorniano e o da maioria dos filósofos que se debruçam sobre o fenômeno estético. A compreensão imanente da linguagem musical o coloca em posição única ao analisar esse fenômeno, pois não o faz do ponto de vista exterior, do esteta, mas, sim, do ponto de vista do compositor e intérprete que era. Sua defesa visceral, e por vezes incompreendida, de uma música dita séria é coerente com a visão da apreciação musical como atividade intelectual, como algo mais complexo que o mero entretenimento.

Por fim, Adorno toca em um ponto nevrálgico: a dificuldade de se apreender, de modo científico, o conteúdo subjetivo da experiência musical. Segundo ele, "o experimento pode atingir os graus de intensidade da reação, mas dificilmente os de qualidade" (2011, p. 59). Para ele, os efeitos fisiológicos e mensuráveis que a música exerce (aceleração ou diminuição dos batimentos cardíacos, por exemplo) não são suficientes para o entendimento da experiência estética de uma obra de arte. Além disso, o próprio uso da linguagem verbal para explicar o que é vivenciado no ato da apreciação também se mostra falho:

A verbalização do vivido musical depara-se, para a maioria dos seres humanos, com obstáculos intransponíveis, na medida em que não se dispõe da terminologia técnica; além disso, a expressão verbal já se acha pré-filtrada, sendo que, para as reações primárias, seu valor cognitivo é duplamente questionável. (ADORNO, 2011, p. 59)

De certa forma, Adorno se antecipa aos estudos da área da neurociência que surgiriam nas primeiras décadas do século XXI, ou seja, cerca de quatro décadas após a publicação desse ensaio. Muitos desses estudos investigam as reações cerebrais aos estímulos musicais e, então, de forma açodada, apresentam conclusões acerca de possibilidades educativas da música que 
têm sido veiculadas com insistência nos meios de comunicação de massa. De forma rápida, uma gama de produtos e serviços é comercializada; em muitos casos, no entanto, novas informações surgem depois, questionando o alcance e, até mesmo, a veracidade das pesquisas anteriormente difundidas.

Esse foi o caso do chamado efeito Mozart (STEELE et al., 1999). Em 1993, os físicos Gordon Shaw e Frances Rauscher, da Universidade da Califórnia, analisaram, em estudantes universitários, os efeitos da audição da Sonata K 448 para dois pianos em Ré Maior, de Mozart. Encontraram uma melhoria temporária do raciocínio espacial-temporal. Em seguida, o termo foi cunhado, por Alfred Tomatis, para o fenômeno do aumento do desenvolvimento cerebral em crianças de até três anos de idade quando ouvem Mozart. Embora nenhum dos dois estudos tenham tido seus resultados reproduzidos, o fato é que a partir de intensa veiculação por meio da internet, uma rede de oferta de produtos foi estimulada: esses vão desde o lançamento de inúmeros livros que visam popularizar esses achados pseudocientíficos, passando por guias para pais e professores, até iniciativas (como as dos governos do Tennessee e da Geórgia) que criaram programas que ofereciam um CD de Mozart para cada recém-nascido, nos respectivos estados norte-americanos. Adorno certamente veria aqui mais uma evidência daquilo que chamou "coisificação da música" (ADORNO, 1983). A diferença em relação ao período analisado por Adorno é que, nos dias atuais, dado o avanço tecnológico, o processo de transformação da música em mercadoria é muito mais rápido e abrangente.

\section{OS DIFERENTES TIPOS DE COMPORTAMENTO MUSICAL}

O primeiro tipo descrito por Adorno é o do ouvinte especialista, ou expert, que é definido por ser detentor de uma escuta adequada por inteiro. Esse comportamento se caracterizaria por apresentar uma escuta estrutural, oposta, de forma absoluta, a uma escuta atomizada e fetichista. O ouvinte teria como horizonte a técnica, mas o domínio dessa o possibilitaria ir além da mesma, a fim de atingir a compreensão do sentido musical:"para aquele que também pensa com o ouvido, os elementos individuais da escuta se tornam imediatamente atuantes como elementos técnicos, sendo que nas categorias técnicas se revela, essencialmente, a interconexão de sentido" (ADORNO, 2011, p. 61). Muito revelador o uso, por Adorno, da expressão daquele que pensa com os ouvidos. Mais uma vez, temos a concepção da fruição estética como atividade reflexiva - o expert, ao ouvir e perceber a composição de forma estrutural, exercita não só sua dimensão sensível mas também suas possibilidades racionais. 
Adorno afirma que esse tipo se limitaria, em tese, ao grupo de músicos profissionais, embora reconheça que o crescente grau de complexidade das composições teria reduzido esse número. O filósofo estaria, com certeza, referindo-se aos movimentos de vanguarda no campo da música erudita, cujos experimentos eletrônicos e acústicos, naquela década, já despontavam. Curiosamente, poderíamos afirmar que, na contemporaneidade, se dá o mesmo fenômeno - o da diminuição do número de ouvintes especialistas - mas por motivo contrário: a baixíssima qualidade das composições produzidas a partir dos cânones da indústria cultural não habilita nem mesmo seus próprios compositores a exercitarem uma escuta estrutural. Com dificuldade poderíamos classificar como ouvintes especialistas os compositores e intérpretes do lixo estético-musical que abunda nos atuais programas de rádio e televisão.

Em seguida, trata Adorno do bom ouvinte. Esse tipo também apresenta uma escuta estrutural: "escuta além do detalhe musical; estabelece interrelações de maneira espontânea e tece juízos bem fundamentados, que não se fiam em meras categorias de prestígio ou no arbítrio do gosto" (2011, p. 63). O fato de não ter ciência de todas as implicações técnicas, como o especialista, não prejudica sua compreensão do fenômeno musical, pois como no caso da língua materna, domina a lógica musical imanente.

Interessante notar, na definição adorniana de bom ouvinte, a prerrogativa do julgamento. Para o filósofo, bom ouvinte é aquele que tem condições de julgar com propriedade, sobre bases intrínsecas à própria linguagem musical. Nos tempos atuais, a capacidade de julgamento parece ter sucumbido: "tudo é relativo", diriam os pós-modernos, sem se darem conta de que essa própria afirmação também precisa ser colocada na forma do relativismo. Quaisquer tentativas de classificação ou juízo de valor são atacadas em nome de uma liberdade que coloca tudo e todos em um mesmo patamar; todo julgamento é visto como autoritário e o lema da impossibilidade da adoção de critérios objetivos para a avaliação de obras de arte ganha adeptos a todo o momento. Nessa mesma direção, Ostrower defende que é possível fazer avaliações estéticas a partir de critérios inerentes à própria linguagem artística:

partimos da premissa de que existem critérios objetivos e de que é possível aplicá-los objetivamente numa visão crítica, sem se deixar levar por simpatias ou antipatias pessoais. [...]. Os critérios básicos de avaliação, os buscamos nos fundamentos da própria linguagem visual, em princípios estruturais que se originam na especificidade desta linguagem e que determinam a expressão. (OSTROWER, 1983, p. 335) 
Assim como Ostrower aponta a possibilidade de se realizar uma avaliação qualitativa nas artes visuais, a partir da complexidade no uso de seus elementos básicos (ponto, linha, luz, sombra, textura, entre outros), acreditamos, com Adorno, que seja possível fazer avaliações estéticas, com base em critérios inerentes à linguagem musical. Também em música, os critérios seriam estabelecidos a partir da análise da maneira como o compositor apresenta, desenvolve e reordena os elementos musicais estruturantes (melodia, harmonia, ritmo, arranjo, entre outros).

Em geral, o bom ouvinte tem experiências formativas em música, como amador. Para Adorno, estaria esse tipo também em declínio, já que as iniciativas musicais dos não profissionais sofreriam a pressão dos meios de comunicação de massa e reprodução mecânica. A sociedade burguesa não estimularia a prática amadora da música da mesma forma que a aristocracia costumava fazer. Atualmente, observa-se uma popularização de métodos e técnicas de aprendizagem musical: pela internet, é possível fazer downloads de métodos, assistir a vídeos de ensaios e ter acesso a programas tutoriais para aprendizagem de instrumentos. Esses abrangem extensa gama em qualidade e gênero: vão de postagens de professores profissionais que pretendem divulgar seus serviços a experiências de aprendizagem juvenis domésticas; de exercícios para fortalecer o quarto dedo para a execução pianística erudita; até vídeos que ensinam os truques para facilitar o toque do carreteiro no tamborim. No entanto, é difícil afirmar que o número de bons ouvintes teria aumentado em função da maior disponibilidade de métodos de aprendizagem musical. O número astronômico de consumidores de produções de baixo valor estético e a pouca frequência a espaços que apresentam música mais elaborada, seja ela popular ou erudita, parecem apontar, ainda, para um número nada significativo de bons ouvintes, no sentido adorniano.

Seria, em nossa opinião, a categoria do bom ouvinte a de maior relevância educacional: formá-lo poderia ser a meta de uma educação musical para a educação básica (NOGUEIRA, 1994). Diferentemente dos conservatórios e escolas de música, a educação musical na escola básica não teria o objetivo de formar profissionais ou especialistas. Apurando apreciadores musicais como bons ouvintes - isso é, indivíduos que por meio de experiências significativas com a linguagem musical pudessem entendê-la e fruí-la de modo mais aprofundado - a escola estaria dando grande contribuição em direção a uma sociedade mais democrática no sentido do acesso aos bens culturais. Formar ouvintes críticos e autônomos poderia ser um eficiente meio de se contrapor à lógica feroz da indústria cultural, que define e nivela por baixo seus consumidores. 
O terceiro tipo de comportamento musical apontado por Adorno seria o do ouvinte de cultura ou consumidor cultural. Seu envolvimento com a música é mais quantitativo que qualitativo:

escuta muito e, sob certas circunstâncias, de modo incessante; é bem informado e coleciona discos. Respeita a música como um bem cultural e, muitas vezes, como algo que deveria conhecer pela própria importância social; tal atitude vai desde o sentimento de respeito sério até o esnobismo vulgar. (ADORNO, 2011, p. 63)

A diferença básica entre esse tipo e os anteriores é que enquanto os primeiros experimentam uma relação com a música, baseada em uma escuta estrutural, aprofundada, o consumidor cultural está mais ligado a um tipo de conhecimento musical periférico, como, por exemplo, dados biográficos dos intérpretes. Em geral, reconhece temas principais das grandes obras, mas sua relação com a música é fetichista, no sentido de escapar-lhe a compreensão mais integral: é, por excelência, o perfeito comprador de coletâneas do tipo highlights e "melhores momentos". É a alegria pelo consumo que o move, sendo mesmo preponderante sobre "a alegria consoante à própria arte e o que essa lhe exige" (2011, p. 64).

Esse tipo, conformista e convencional, assume importante papel na sociedade, pois é dele que parte, em geral, a definição do repertório que é apresentado na vida musical oficial: são os habituais assinantes de teatros e casas de óperas, membros de agremiações e grupos de amigos ligados a entidades do campo da cultura. Adorno acrescenta ainda a esse grupo "as damas americanas dos comitês de concertos filarmônicos" (p. 64). Tendo em mente a programação de música erudita dos grandes centros brasileiros, percebe-se o quão atual é essa categoria que patrocina as notáveis orquestras e teatros, formada por membros de famílias influentes não apenas no cenário cultural, mas principalmente na vida econômica e política. Assim como na década de 1960, no século XXI, esse tipo de ouvinte, elitista e conservador, desempenha um papel controlador:

induzem àquele gosto reificado que, sem razão de ser, sente-se superior ao gosto da indústria cultural. Mais e mais, os bens culturais musicais administrados por esse tipo se transmudam nos bens atinentes ao consumo manipulado. (ADORNO, 2011, p. 65)

O quarto tipo de ouvinte apontado por Adorno é o ouvinte emocional. Adorno deixa transparecer certo desprezo por esse tipo, uma vez que, para ele, o ato de ouvir música (como antes já afirmamos) é mais que um deixar-se 
abandonar pelo enlevo e, sim, uma atividade integradora, sensível e racional ao mesmo tempo.

A relação desse ouvinte com a música se dá menos pelo conhecimento dos elementos da linguagem musical e mais pelo que ela mobiliza em seu psiquismo: o que ouve "se transforma para ele em expediente essencial para a ativação de excitações instintivas reprimidas ou domadas pelas normas civilizatórias" (p. 65). Por seu caráter pouco reflexivo, ele se coloca em posição de alvo preferencial da indústria cultural: "o caráter imediato de sua reação acompanha uma cegueira, às vezes taciturna, diante das coisas às quais reage. Não quer saber de nada e, por isso, é desde o início fácil de comandar" (p. 66).

Seu envolvimento com a música se estabelece a partir de suas carências, pois esses ouvintes

gostariam de utilizar a música como um receptáculo no qual pudessem derramar as próprias emoções amedrontadas, ou, conforme a teoria psicanalítica, as emoções livremente flutuantes; noutras ocasiões, por meio da identificação com a música, desejariam atrair para essa última as emoções que sentem falta em si próprios. (ADORNO, 2011, p. 67)

Esse ouvinte mostra-se bastante familiar em nossa sociedade atual. Podemos exemplificá-lo com os ouvintes de certas cantoras/apresentadoras de TV que - por terem tido a infância marcada pelo consumo acrítico desse tipo de produção comercial - permanecem fiéis aos ídolos e, mesmo diante das evidências do baixo nível estético de suas produções, insistem em defendê-los com argumentos nostálgicos. Muitas vezes, reagem contra um tipo de escuta mais aprofundada, pois esta "é confundida com um comportamento frio e extrinsecamente reflexivo diante da música" ( $p$. 67). Com frequência, deparamo-nos com esse tipo de ouvinte em cursos de formação continuada para professores generalistas. Ao perceberem os limites estéticos e educativos das produções que ouviam (e continuam apresentando a seus alunos), colocam-se em posição refratária, acusando de elitistas aqueles que buscam ampliar seus referenciais musicais, a partir da apreciação de obras mais elaboradas: "com ímpeto, o tipo emocional opõe-se às tentativas de ensejar-Ihe uma escuta estrutural" (p. 68). Essa citação mostrase assaz emblemática do que acontece nesses cursos nos dias atuais: certos professores se colocam como fãs e defensores de seus ídolos de infância, mesmo em detrimento de uma melhoria no repertório a ser vivenciado com seus alunos, tornando inócuos os esforços em direção a uma educação musical efetivamente emancipadora.

Em seguida, Adorno trata de um tipo oposto ao anterior: o ouvinte do ressentimento. Nesses dois casos - do ouvinte emocional e o ouvinte 
do ressentimento -, a classificação se coloca mais na perspectiva de uma psicologia da audição que propriamente em uma sociologia da música, como nos demais tipos. O ouvinte do ressentimento seria avesso à emotividade barata despertada pela música, como no caso do ouvinte emocional. Esse tipo

desdenha a vida musical oficial como algo desgastado e ilusório; não trata, porém, de ir além dela, senão que foge para trás em direção a períodos que acredita estarem protegidos contra o caráter mercadológico dominante, contra reificação. (ADORNO, 2011, p. 68)

Em geral, os ouvintes ressentidos reúnem-se em grupos sectários e refratários. Adorno já os havia apresentado em seu ensaio Em defesa de Bach contra seus admiradores, escrito originalmente em 1951, isso é, uma década antes do ensaio sobre a tipologia dos ouvintes. O filósofo afirma, então, que essas pessoas apreciam a ordem da obra de Bach não por suas qualidades musicais, mas porque necessitam seguir a uma ordem: "a Bach se apegam todos aqueles que, por terem perdido a fé ou a autodeterminação, ou por não estarem mais aptos a exercê-la, buscam uma autoridade que lhes assegure a desejada segurança" (ADORNO, 1998, p. 131). Ficam explícitos aqui os contornos psicológicos, mais que sociais, desse tipo de ouvinte.

Outro tipo com características semelhantes ao ouvinte do ressentimento seria o ouvinte de jazz, pois esse também costuma se organizar em confrarias e adota comportamento sectário: "qualquer comentário crítico sobre o jazz é interpretado pelo círculo interno como sacrilégio por parte de um não iniciado" (ADORNO, 2011, p. 73). A ironia fina do autor em relação aos amantes de jazz talvez explique a reação até hoje indignada contra seus comentários e análises.

Para Adorno, esse tipo se enxerga como vanguardista, quando, na verdade, muitas das pretensas ousadias já teriam sido realizadas pela música erudita, décadas antes. Isso, quem sabe, possa ser explicado pelo próprio fechamento desse grupo: ouvindo exclusivamente o mesmo gênero, acaba por desconhecer o que acontece em outros campos da música. Nesse sentido, "a alienação relativa à cultura musical sancionada remonta, nesse tipo, a uma barbárie pré-artística que se revela, sem mais nem menos, como o irromper de sentimentos primordiais" (2011, p. 75). Nos dias de hoje, outros tipos de ouvintes, não só do jazz, adotam posições semelhantes, encastelando-se em locais alternativos para consumir música como em um ritual religioso.

De todas as nomenclaturas de categorias, talvez essa seja a mais difícil de se manter atual, por vários motivos. Primeiro, porque o jazz a que Adorno se referia sofreu muitas mudanças e, de certa forma, superou algumas das críticas que Adorno teria elaborado: uma rápida observação acerca dos 
programas dos festivais de jazz que acontecem pelo mundo atesta uma grande diversidade, inclusive com qualidade muito superior ao repertório clichê que o filósofo ouviu em sua estadia nos Estados Unidos. A expressão free jazz talvez possa refletir essa ampla gama de estilos que estão reunidos sob esse gênero. Em segundo lugar, é necessário lembrar sempre que a fúria adorniana estava centrada na música proveniente da indústria cultural, isso é, na música de entretenimento, no hit comercial e raso, nos standards jazzísticos previsíveis. Naquela ocasião, o jazz de apelo comercial, divulgado como mercadoria ideológica do american way of life, era a expressão dessa música coisificada; esse era o alvo de sua análise. Da mesma forma, se hoje alguém criticasse o samba apresentado nos shows de mulatas para turistas, não estaria fazendo ressalvas ao samba de raiz ou mesmo ao samba como gênero popular: estaria criticando a comercialização imputada pela indústria cultural que pasteuriza e empobrece as manifestações artísticas, por mais legítimas que essas possam ser.

No entanto, como exercício reflexivo, pensar esse tipo de ouvinte não só como o de jazz, mas como o de um ouvinte sectário, muito próximo ao ouvinte do ressentimento, o colocaria em parâmetros mais contemporâneos.

O mais numeroso de todos os tipos é, com segurança, o ouvinte de entretenimento: em termos estatísticos, tanto na década de 1960 e principalmente agora, quando a educação musical parece estar fora dos interesses prioritários das famílias, ele é, por certo, o mais proeminente. Sua relevância também se deve a seu papel na sociedade capitalista: "o ouvinte do entretenimento é aquele pelo qual se calibra a indústria cultural, seja porque ela o engendra ou o traz à tona" (2011, p. 75). Ele se aproxima, em certo sentido, do tipo consumidor cultural, pois para ele"a música não consiste em uma estrutura de sentido, mas em uma fonte de estímulo" (p. 76); permanece horas a fio ligado a um meio de reprodução musical: no contexto de Adorno, ao rádio; nos dias atuais, aos variados meios digitais. No entanto, sua escuta é passiva, superficial; liga-se aos refrões ou trechos mais conhecidos, mas, via de regra, mal consegue analisar a letra do que está sendo cantado.

Adorno aproxima o comportamento desse ouvinte ao do viciado, tal sua dependência musical. Isso poderia ser observado no comportamento

daquele que deixa o rádio ligado enquanto, ao mesmo tempo, põe-se a trabaIhar. Em termos históricos, essa atitude desconcentrada está, desde há muito, preparada pelo ouvinte de entretenimento, sendo, de resto, sustentada de diversas maneiras pelo material relativo a tal escuta. (ADORNO, 2011, p. 77)

Por ser a categoria de maior número, Adorno levanta a possibilidade de que ela possibilitaria uma classificação interna, indo desde o tipo descrito 
anteriormente, que não pode trabalhar sem música, até aquele que a utiliza como relaxamento, passando por tipos de músicos provincianos amadores. Esse ouvinte costuma reagir contra o esforço de uma escuta mais reflexiva: "ele é um low-brow consciente de si mesmo, que faz de sua mediocridade uma virtude" (2011, p. 78). Impossível não reconhecer a permanência desse tipo em nossa sociedade, em número cada vez maior, cujo consumo acrítico de tudo o que a indústria fonográfica lança a cada estação enriquece os executivos de gravadoras e músicos medíocres, na mesma proporção que os afasta de experiências estéticas poderosas e transformadoras.

Por fim, Adorno identifica uma última categoria, os musicalmente indiferentes, não musicais ou antimusicais. Seu comportamento teria origem em fatos ocorridos na primeira infância, em que uma autoridade brutal ou muito rígida seria responsável por um trauma. O filósofo não se alonga na análise desse tipo, afirmando, mesmo, que a falta de musicalidade seria tema para futuras investigações. Talvez essa seja a categoria menos expressiva, não só por sua relação quase inexistente com a música, o que nem mesmo poderia classificá-lo como "ouvinte", mas também por ter sido a menos desenvolvida pelo autor.

\section{Conclusão}

Os estudos acerca da música tomam parte importante na obra de Adorno, não só no aspecto quantitativo mas, principalmente, qualitativo. Sua densa formação musical, conjugada à reflexão filosófica original, o habilita a analisar o fenômeno da escuta musical de forma única. Embora seja possível promover análises sobre a atualidade de alguns detalhes, uma vez que o próprio Adorno conclama a isso em sua apresentação, é inegável a relevância e permanência de tais estudos, no sentido de auxiliar a revelar as nuances de comportamento pelas quais a indústria cultural baliza seus instrumentos. No campo da educação, ao qual nos filiamos, torna-se também primordial refletir sobre essas categorias, no sentido de buscar como meta a formação de um ouvinte autônomo e consciente, ou seja, adornianamente falando, um bom ouvinte.

ADORNO AND HIS CLASSIFICATION OF MUSICAL BEHAVIOR TYPES: ACTUALITY AND LIMITS

ABSTRACT: This article reflects on the actuality of the classification of types of musical behavior, drawn up by T. W. Adorno, in the 1960s. In his original essay, he presents eight kinds of listener: the expert listener, the good listener, the culture consumer, the emotional listener, the resentful listener, the jazz expert, the entertainment listener 
and the indifferent. When drawing up these categories, he used elements which are specifically musical, as well as social and psychological elements. Because of the intense transformation in patterns of listening brought about by the expanding technological revolution, it could be assumed that Adorno's classification would no longer be valid. However, the study concludes that a large part of his analysis is still valid and relevant, because there are few anachronisms. What stands out is that the process of regression of listening and reification of music by the cultural industry still remain active and destructive.

KEYWORDS: Musical behavior. Critical theory. Sociology of music.

\section{ADORNO Y LOS TIPOS DE COMPORTAMIENTO MUSICAL: ACTUALIDAD Y LÍMITES.}

RESUMEN: El presente artículo busca instigar una reflexión sobre la actualidad de la clasificación de los comportamientos musicales, hecha porT.W. Adorno, en la década de los sesenta del siglo pasado. En su ensayo original, el filósofo señala ocho tipos de oyentes: el especialista, el buen oyente, el consumidor cultural, el oyente emocional, el oyente del resentimiento, el oyente de jazz, el oyente del entretenimiento y el indiferente. Al realizar esta categorización, Adorno hace uso tanto de elementos propiamente musicales, como fundamentos sociológicos y psicológicos. Ya que una intensa modificación en los padrones de escuchar se dio a partir de la creciente revolución tecnológica, se podría suponer que esta clasificación se presentase inválida. Sin embargo, se puede concluir que buena parte de su análisis permanece actual y relevante, pues los posibles anacronismos son puntuales. Lo que se destaca es que los procesos de regresión de la audición y de la cosificación de la música por parte de la industria cultural permanecen activos y devastadores.

Palabras claves: Comportamiento musical. Teoria crítica. Sociologia de la música.

\section{REFERÊNCIAS}

ADORNO, T. W. O fetichismo na música e a regressão da audição. 2. ed. São Paulo: Abril Cultural, 1983. (Coleção Os Pensadores).

. Em defesa de Bach contra seus admiradores. Prismas - crítica cultural e sociedade. São Paulo: Ática, 1998. . Introdução à sociológica da música. São Paulo: Unesp, 2011.

HORKHEIMER, M.; ADORNO, T. W. Dialética do esclarecimento. 2. ed. Rio de Janeiro: Jorge Zahar, 1986.

NOGUEIRA, M. A. A formação do ouvinte como um direito do cidadão: propostas para a educação musical no ensino fundamental. Dissertação (Mestrado) - Faculdade de Educação da UFG, Goiânia, Goiás, 1994. 
OSTROWER, F. Universos da arte. 17. ed. Rio de Janeiro: Campus, 1983.

STEELE, K. et al. The mystery of the Mozart effect - failure to replicate. Psychological Science, v. 10, n. 4, July 1999.

MONIQUE Andries NogueIRA é doutora em Educação pela Universidade de São Paulo; professora associada da Faculdade de Educação da Universidade Federal do Rio de Janeiro e membro permanente do Programa de Pós-Graduação em Educação; coordena o Grupo de Estudos e Pesquisas em Educação, Arte e Cultura (GECULT) do Laboratório de Estudos e Pesquisas em Didática e Formação de Professores (LEPED).

E-mail: andries@terra.com.br 